\title{
Appropriately Selected Nerve in Suspected Leprous Neuropathy Yields High Positive Results for Mycobacterium leprae DNA by Polymerase Chain Reaction Method
}

\author{
Seena Vengalil, ${ }^{1}$ Mallika Lavania, ${ }^{2}$ Itu Singh, ${ }^{2}$ Saraswati Nashi, ${ }^{1}$ Veeramani Preethish-Kumar, ${ }^{1}$ Kiran Polavarapu, ${ }^{1}$ \\ Niranjan Prakash Mahajan, ${ }^{1}$ Sanita Raju, ${ }^{1}$ Chevula Pradeep-Chandra-Reddy, ${ }^{1}$ Muddasu Keerthipriya, ${ }^{1}$ Anita Mahadevan, ${ }^{3}$ \\ Tagadur Chickabasaviah Yasha, ${ }^{3}$ Bevinahalli Nandeesh, ${ }^{3}$ Krishnamurthy Gnanakumar, ${ }^{3}$ Gareth J. Parry, ${ }^{4}$ Utpal Sengupta, ${ }^{2}$ \\ and Atchayaram Nalini ${ }^{1 *}$ \\ ${ }^{1}$ Department of Neurology, National Institute of Mental Health and Neurosciences, Bangalore, India; ${ }^{2}$ Stanley Browne Research Laboratory, TLM \\ Community Hospital, New Delhi, India; ${ }^{3}$ Department of Neuropathology, National Institute of Mental Health and Neurosciences, Bangalore, India; \\ ${ }^{4}$ Department of Neurology, St John's Medical College, Bangalore, India
}

\begin{abstract}
Identification of Mycobacterium leprae DNA by polymerase chain reaction (PCR) is a reliable and an affordable method to confirm leprosy. DNA from 87 nerve samples (61 from paraffin blocks and 26 fresh samples) was extracted. Mycobacterium leprae DNA was amplified by PCR from 80/87 (92\%) specimens. Patients were seen over a period of 11 years (2007-2019), and leprosy was diagnosed based on clinical and characteristic histopathology findings. The clinical diagnostic possibilities were as follows: leprous neuropathy in 73/80 (91.3\%), mononeuritis multiplex of unknown etiology in four (5.0\%), vasculitic neuropathy in two $(2.5 \%)$, and distal symmetric sensory motor neuropathy in one $(1.3 \%)$. The biopsied nerves were as follows: superficial radial $=34(42.6 \%)$, dorsal cutaneous branch of ulnar $=19$ $(23.8 \%)$, sural $=18(22.5 \%)$, and superficial peroneal $=9(11.3 \%)$, and corresponding neurological deficits were recorded in $77(96.3 \%)$ cases. The histopathological diagnoses in total group were as follows: (borderline tuberculoid $(B T)=52$, tuberculoid $(T T)=8$, borderline lepromatous $(B L)=8$, borderline borderline $(B B)=3$, nonspecific inflammation $=3$, healed/ fibrosed $=4$, and axonopathy $=2$ ). Acid fast bacilli (AFB) was demonstrated in $11(13.7 \%)$ samples. For comparison, 31 clinically and histopathologically defined non-leprous disease control nerves (inherited neuropathy $=20$, vasculitis $=8$, and nutritional neuropathy $=3$ ) subjected to PCR were negative for $M$. leprae DNA. In most instances, there are multiple thickened peripheral nerves in suspected cases of leprosy, but neurological deficits pertaining to the thickened nerve are not as widespread. The current findings emphasize the importance of selecting the most appropriate nerve for biopsy to obtain a positive PCR result. We infer that clinical, histopathological, and PCR tests complement each other to help achieve a definitive diagnosis of leprosy particularly in pure neuritic leprosy and in leprous neuropathy with negative skin smears/biopsy.
\end{abstract}

\section{INTRODUCTION}

Leprosy or Hansen's disease, an ancient mycobacterial disease, results from the uncultivable pathogen Mycobacterium leprae. ${ }^{1}$ Although the prevalence of leprosy in India is less than $1 / 10,000$ since 2005 , it still accounts for $62 \%$ of the total new cases reported worldwide, ${ }^{2}$ and more than $81 \%$ of the new cases are reported from three countries-India, Brazil, and Indonesia. ${ }^{3}$

Since the implementation of multidrug therapy, the prevalence of leprosy has significantly reduced worldwide, but because of the occurrence of permanent disabilities and sequelae, leprosy still represents a serious health problem in the developing countries. ${ }^{4}$

The $M$. leprae bacillus causes mononeuropathy, multiple mononeuropathy, and symmetrical neuropathy, resulting in autonomic, sensory, and motor dysfunction. The peripheral neural impairment includes nerve trunks as well as distal cutaneous branches. Sensory symptoms often are the most common and initial complaints. ${ }^{5-8}$

In addition, up to one-fourth develop neuropathy during or after treatment. ${ }^{9}$

Worldwide, more than three million people are living with disabilities due to leprosy. ${ }^{10}$ Early detection and correct treatment of neuropathy is imperative to prevent permanent neurological disabilities. It is also observed that when sensory impairment is clinically detectable, significant damage has

\footnotetext{
${ }^{*}$ Address correspondence to Atchayaram Nalini, Department of Neurology Neuroscience Faculty Center, National Institute of Mental Health and Neurosciences, Marigowda Road, Bengaluru
} 560029, India. E-mail: atchayaramnalini@yahoo.co.in already occurred to the nerves. ${ }^{11}$ Primary neural leprosy (PNL), also known as pure neural or neuritic leprosy form, was initially described in the Indian classification published in $1955 .^{12}$ Since then, it is considered a challenge to clinicians. This clinical form is characterized by absent skin lesions and negative slit skin smear (SSS) on bacilloscopy. Therefore, diagnosis is mainly based on supplementary tests, such as electroneuromyography, nerve biopsy, serology, and molecular analyses. ${ }^{13-18}$

Presence of minimal symptoms at disease onset frequently leads to diagnostic errors and underdiagnosis/misdiagnosis of the neural form. In such cases, polymerase chain reaction (PCR) testing for $M$. leprae DNA helps in establishing an early diagnosis and timely treatment. ${ }^{13,19,20}$

In the current study, extending over a period of 11 years (2007-2019), we procured 87 specimens of peripheral nerve tissue from clinical and histopathologically defined cases of leprosy. We report on the identification of $M$. leprae DNA from preserved as well as fresh nerve samples by PCR method (61:26). Here, we stress that selection of the peripheral nerve associated with corresponding neurological deficits results in good yield of $M$. leprae DNA by PCR.

\section{MATERIALS AND METHODS}

Study subjects. This study was conducted at the National Institute of Mental Health and Neurosciences (NIMHANS) Bangalore, located in the southern part of India. It is a quaternary care center for all neurological disorders. Here, cases with predominantly pure neuritic form of leprosy or leprous neuropathy with negative SSS and those with neuropathy and unnoticed skin lesions attend the outpatient clinics. 
We scrutinized the neuropathology records with a diagnosis of leprosy maintained over a period of 11 years (2007-2019). The clinical criteria applied were as follows: presence of a sensory and autonomic/sensory motor and autonomic neuropathy with or without skin lesions. We identified 102 retrospective relevant histopathology reports. Of these, 61 paraffin blocks were available. Prospectively, 26 fresh nerve samples stored in RNAlater solution made up a total of 87 samples for the study. We also selected 31 non-leprosy nerve tissue samples as negative controls and subjected the tissue to PCR for M. leprae DNA.

Ethics statement. As part of the hospital requirement, all patients provide consent for minor procedures such as nerve and muscle biopsy during registration at the outpatient clinic. All patients included in the prospective group gave written informed consent for biochemical tests and biopsy procedure as part of diagnostic tests. Ethics approval from "NIMHANS ethics committee" (Institutional Review Board) was obtained to collect all clinical, biochemical, and histopathological characteristics from the hospital medical records and also for processing stored nerve tissue for PCR study.

Detection of $\boldsymbol{M}$. leprae DNA by PCR. All samples of DNA isolated from the preserved nerve tissue and the fresh nerve tissue stored in RNAlater solution were tested at Stanley Browne Laboratory, the Leprosy Mission Trust India at New Delhi. Nerve tissue from paraffin blocks were subjected to FFPE DNA (M/s. Analytik Jena AG, Jena, Germany) kit method for DNA extraction. Mycobacterium leprae-specific DNA was amplified by PCR method. Of the 87 specimens tested, PCR amplified the $M$. leprae DNA from 80 samples, including the 26 fresh nerve tissue samples preserved in RNAlater solution.

Polymerase chain reaction methodology. Polymerase chain reaction-based gene amplification was performed using primers according to the guidelines of the WHO.

"Global Surveillance of Drug Resistance in Leprosy 2008" for the detection of mutation in rpoB, gyrA, and folP1genes in $M$. leprae genome. The PCR mixture contained 12.5- $\mu \mathrm{L}$ Hot Start Taq polymerase PCR master mix (2x) (Qiagen, Hilden, Germany), 1.25 of $\mu \mathrm{L}$ forward primer and reverse primer at a final concentration of $0.5 \mu \mathrm{M}$, and $5 \mu \mathrm{L}$ of template DNA from the processed sample. The final volume of reaction mix was made up to $25 \mu \mathrm{L}$ with nuclease-free water. Primer sequences used in this study were as follows: folP primers folPF CTTGATCCTGACGATGCTGT; folPR CCACCAGACACATCGTTGAC, rpoB primers rpoBF GTCGAGGCGATCACGCCGCA; rpoBR CGACAA TGAACCGATCAGAC, and gyrA primers gyrAF ATGGTCTCAAACCGGTACATC; gyrAR TACCCGGCGAACCGAAATTG. The reaction was cycled 40 times at $94^{\circ} \mathrm{C}$ for 1 minute, $60^{\circ} \mathrm{C}$ for 1 minute, and $70^{\circ} \mathrm{C}$ for 1 minute, which is preceded by initial denaturation at $95^{\circ} \mathrm{C}$ for 15 minutes and ended by final extension at $72^{\circ} \mathrm{C}$ for 10 minutes.

Each reaction setup contained one negative and one positive control. Detection of PCR product was performed on a $2 \%$ agarose gel, and amplicons were excised from the gel and purified by using the Qiagen Gel Extraction Kit.

\section{RESULTS}

All patients were referred to our center with symptoms of neuropathy and underwent nerve biopsy for confirming the aetiological diagnosis. Based on the clinical and nerve histopathology findings, 87 cases of leprosy were selected for this study. DNA could be isolated from all the 87 nerve tissue specimens. Mycobacterium leprae-specific DNA could be amplified by PCR from 80 of the 87 (92\%) specimens, and these were included for the final analysis. The seven patients' DNA samples not amplified by PCR were also diagnosed to have leprosy by histopathology: (healed leprosy $=2$, lepra reaction $=1$, and borderline tuberculoid $[B T]=4$ [one showed AFB]). There were 56 drug-naive cases, whereas 24 were on variable periods of MDT (range, 6 months to 2 years) at the time of biopsy. Among the 80 cases, the clinical diagnoses were as follows: mononeuritis multiplex suggestive of leprous neuropathy in $73 / 80(91.3 \%)$, mononeuritis multiplex with no definitive diagnostic signs of leprosy in four (5.0\%), possible vasculitic neuropathy in two (2.5\%), and distal symmetric sensory motor neuropathy in a HIV-positive case (1.3\%). The 24 patients already receiving multi drug therapy (MDT) for leprosy had developed fresh signs of neuropathy and had no features to suggest lepra reaction.

For the entire group, the mean age at the onset of disease, age at presentation, and duration of illness was $35.4 \pm 12.9$ (10-71) years, $37.8 \pm 13.3(14-71)$ years, and 4.7 years (1 month to 24 years), respectively. Burning paresthesias in distal extremities was reported in 39 cases (48.8\%), tingling paresthesias in 25 (31.3\%), and numbness in 24 (31.2\%). Ulnar nerve was the most prominently and commonly observed thickened nerve followed by superficial radial and sural. Painful tender nerves were present in $54(67.5 \%)$ cases. Skin lesions were reported in 27 (33.7\%), but examination revealed skin changes in 42 patients (hypopigmented macules in 42 [52.5\%] patients, skin nodules in 11 [13.8\%], and painless foot ulcers in 18 [22.5\%]). Thus, patients had features of mononeuritis multiplex with predominant involvement of the upper limbs. Slit skin smears had been performed in 15 patients from the referring hospital and reported as negative for lepra bacilli. Skin biopsy performed by prior treating dermatologists was available in 18 (22.5\%) cases; granulomas with no AFB were seen in four, nonspecific inflammation in seven, and no diagnostic pathology in seven cases. We had no access to the slides for review. The biopsied nerves in our cohort were superficial radial in 34 (42.6\%), dorsal cutaneous branch of ulnar nerve in 19 (23.8\%), sural nerve in 18 (22.5\%), and superficial peroneal nerve in nine (11.3\%) (Figure 1). The peripheral nerve with deficits in its area of supply was biopsied in 77 (96.3\%) cases. The histopathological diagnosis were as follows: $(B T=52, T T=8, B L=8, B B=3$, nonspecific inflammation $=2$, healed/fibrosed $=3$, and axonopathy $=1$ ), whereas only the thickened nerve was biopsied in three cases (healed leprosy = 1 , nonspecific inflammation $=1$, and axonopathy $=1$ ) (Figure 2). AFB was demonstrated in 11 (13.7\%) cases. One of these patients with mild axonopathy in the thickened superficial radial nerve had no corresponding deficits. However, fine needle aspiration material of the ulnar nerve abscess revealed $M$. leprae DNA. Histopathologically, perineural thickening was seen in 78 (97.6\%), endoneural fibrosis in 75 (93.8\%), lymphocytes in 74 (92.6\%), perivascular inflammation in $73(91.3 \%)$, histiocytes in 42 (52.5\%), foam cells in $28(35.1 \%)$, giant cells in $20(25.1 \%)$, granulomas in 22 (27.5\%), plasma cells in 19 (23.8\%), and caseous necrosis in eight $(10.0 \%)$ biopsies (Figure 3 ). Polymerase chain reaction performed in the disease control nerves was negative for M. leprae DNA in all 31 samples. 


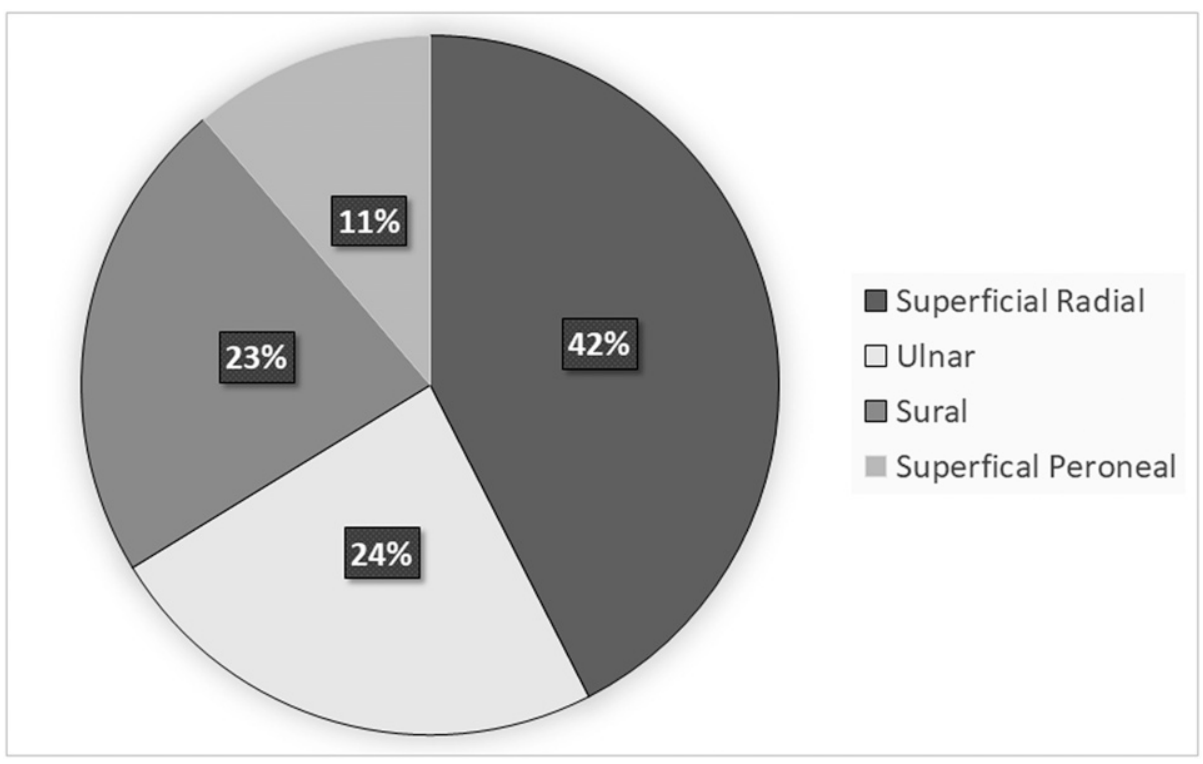

FigURE 1. Selection of the nerve for biopsy.

\section{DISCUSSION}

There are a limited number of studies assessing the importance of identification of PCR-based M. leprae DNA from predominantly neural form and pure neural leprosy. This was an ambispective study on nerve tissue samples collected over a period of 11 years. The main aim was to identify $M$. leprae DNA by PCR technique in DNA isolated from biopsied peripheral nerve tissue preserved in paraffin block and fresh nerve tissue collected in RNAlater solution. The total number of DNA samples subjected for PCR was 87 , and in 80 samples, M. leprae DNA could be amplified. We also studied 31 nonleprous nerve tissues as negative controls.

Over the last two to three decades, detection and identification of $M$. leprae DNA in various tissues has proven to be a useful tool in diagnosing leprosy. ${ }^{21-23}$ Direct detection of AFB in slit-skin smears has a high specificity but low sensitivity, as approximately $50 \%$ of all leprosy patients are SSS negative. ${ }^{24,25}$ In the current cohort, SSS was negative in all cases when it was performed, and skin biopsy revealed nonspecific granulomas in only $4 / 18$ cases, and none showed

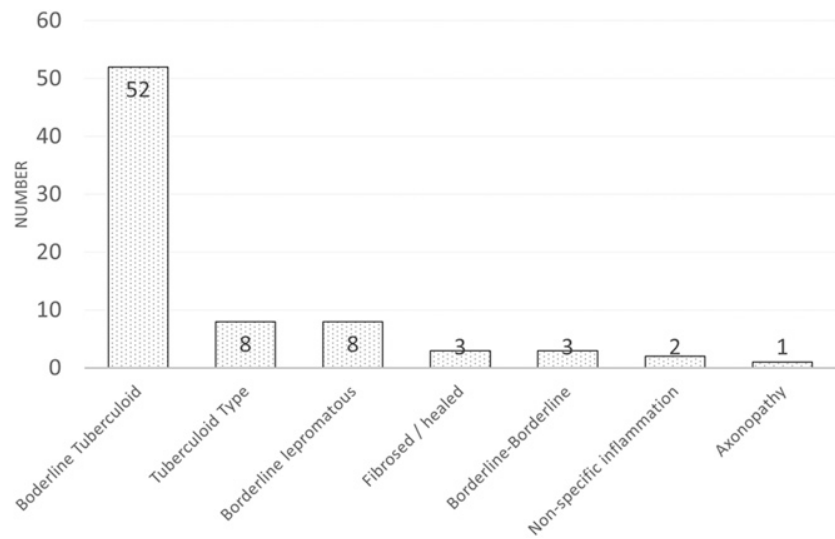

FIGURE 2. Bar diagram showing the type of leprosy based on the nerve histopathology findings.
AFB. Thus, no definitive diagnosis of leprosy could be made from SSS and skin biopsy even in cases with skin lesions.

Leprosy patients lacking skin manifestations, but having involvement of one or more nerves, are afflicted with pure neural leprosy (PNL), which accounts for 3.9-8.2\% of all leprosy patients in India. ${ }^{26-28}$ Generally, the diagnosis of leprosy is clinical and depends on the presence of hypoesthetic skin lesions, thickened peripheral nerves with sensory motor and autonomic neuropathy, and supplemented by demonstration of AFB in skin/nasal smears/nerve biopsies. Definite histopathological features showing pathological alteration in nerve specimens along with AFB are seen in only $35 \%$ of early cases. ${ }^{29}$ In our cohort, such a definitive diagnosis was possible in only $11(13.7 \%)$ cases, which is far less compared with the aforementioned report. In our highly biased cohort, PNL comprised $50 \%$ of cases (40/80), and four (10\%) of the 40 were reported as healed leprosy/fibrosed nerve. These patients predominantly had symptoms related to neuropathy and hence consulted our neurology services. Curiously, several patients and the treating physicians did not notice the skin lesions.

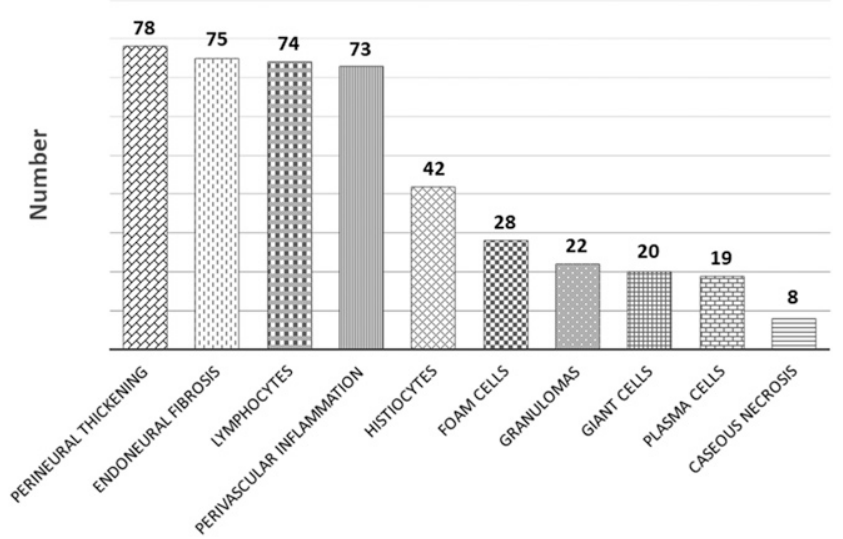

FIGURE 3. Bar diagram showing the histopathology findings as demonstrated on nerve biopsy. 
There are very few reports in the English literature with regard to pure neural leprosy (PNL) and its diagnostic workup. ${ }^{27,28,30-33}$ Confirming the diagnosis in PNL is challenging even for experts in peripheral nerve disorders, and it is not uncommon to mislabel/wrongly treat patients because of nerve biopsy being reported as inconclusive/nonspecific inflammatory findings. In our cohort, PNL was diagnosed in almost $50 \%$ of the cases, and treatment was based purely on histopathology characteristics in the retrospective group.

The use of PCR for the detection of $M$. leprae DNA in nerves has proved to be very useful in confirming PNL. ${ }^{22,34-36}$ Polymerase chain reaction has been found to be especially valuable in paucibacillary disease and in patients with atypical clinical presentation and histopathological features compatible with leprosy. ${ }^{37}$ Our prospective group benefited most with a definitive diagnosis of leprosy based on PCR confirmation and, thus, correct treatment for patients of leprous neuropathy with negative AFB in nerve biopsy. Therefore, PCR-based M. leprae identification plays an important role in the diagnosis of neural form of leprosy. In our latest publication, we confirmed patients with peripheral neuropathy and central nervous system lesions to have leprosy through PCR on DNA from nerve tissue. ${ }^{38}$

Histopathological confirmation is often difficult in PNL because of the low sensitivity and absence of AFB in the biopsy specimen, particularly in the tuberculoid type. In our cohort, 77 cases had biopsies of nerves that had deficits in its distribution. However, nine nerve samples showed no diagnostic features of leprous neuropathy on histopathology, but did reveal $M$. leprae DNA by PCR. The amplification of $M$. leprae DNA in 80 of 87 tested samples indicates a high yield when compared with previous reports. Nevertheless, one AFB-positive nerve sample failed to reveal M. leprae DNA. This could possibly be due to improper DNA or loss of DNA during the cleanup process of PCR product. However, such discordance has been reported in a previous study. ${ }^{39}$ Histopathological features similar to that observed in tuberculoid PNL can also be seen in chronic inflammatory demyelinating neuropathy, vasculitic/noninfective granulomatous neuropathy, and neurosarcoidosis. Clinically, the disease could also mimic hereditary sensory and autonomic neuropathy and needs to be differentiated. Furthermore, impaired kinaesthesia and variable stretch reflexes particularly those with hyperactive tendon reflexes may mislead clinicians toward a wrong diagnosis. ${ }^{40}$ In this same study from our institute, 36/133 patients with biopsy-proven leprosy were suspected to have neuropathy other than leprosy, ${ }^{40}$ implying a high degree of misdiagnosis at the bedside.

In clinically and histopathologically undefined neuropathy cases, it may be imperative to subject tissue samples for the presence of $M$. leprae DNA by PCR method. Although this technique is available in highly specialized centers, it is a simple and cost-effective diagnostic method, and its availability needs to be known to physicians.

In a report from Northern India, PCR performed in nerve tissue from 35 PNL cases revealed $M$. leprae DNA in $22(62 \%)$. Polymerase chain reaction was positive in 12/13 AFB-positive cases and in 10/22 with no AFB. ${ }^{39}$ In comparison among our 87 histopathologically diagnosed leprosy cases, 80 samples showed M. leprae DNA, and the four cases with fibrosed/ healed nerve tissue and one with only axonopathy also demonstrated M. leprae DNA. However, isolating DNA for PCR in fibrosed/healed tissue may not be successful always. It is clearly evident that the PCR yield was significantly higher, including the group with BT and TT leprosy in our series.
In another study from this same group, in 67 nerve biopsies from PNL patients presenting as mononeuritis multiplex, histopathology showed epithelioid granuloma in 14\%, AFB in $16 \%$, and nonspecific inflammatory infiltrate and/or fibrosis in $39 \%$ of cases. Polymerase chain reaction for $M$. leprae was positive in $47 \%$ of 23 nerve specimens. ${ }^{39}$ In comparison, in our patients, PCR amplified $M$. leprae DNA in more than $90 \%$ of samples. Subjecting nerve biopsies for PCR analysis has been reported several decades ago when $M$. leprae DNA was observed in all lepromatous leprosy patients, and the majority were paucibacillary cases. ${ }^{41}$ In our cohort, most had BT type leprosy, but all types demonstrated $M$. leprae DNA.

In a study from Brazil, in 58 patients of PNL, PCR was positive from 29 patients $(50 \%) .{ }^{19}$ In comparison our PCR positive rate was more than $90 \%$ and was high even in the AFB negative group. Antunes et al., from Brazil identified that 28 of their 92 AFB negative nerve biopsy samples showed a positive PCR test while PCR was negative in all the non-leprous samples emphasizing its high specificity for confirming M. leprae infection. ${ }^{42}$ Similarly among our 31 clinically and histopathologically defined non-leprous cases PCR was negative for $M$. leprae DNA reiterating the specificity of PCR testing. Above authors also mention that the 'probable' PNL benefits most from an additional molecular investigation on the same biopsy tissue. Similar findings have been reported in earlier studies on nerve and skin biopsy specimens. ${ }^{19,43}$ In our cohort we found that PCR revealed $M$. leprae DNA in a higher percentage of non-AFB cases.

In the recent years, high-resolution sonography of peripheral nerves is projected as an informative and additional diagnostic tool for leprosy. Thickened epineurium noted in the ulnar nerve, which is the most commonly affected nerve, and altered echotexture of the nerves with increased epineural blood flow on color Doppler may provide clues toward the diagnosis of leprosy. ${ }^{44,45}$

\section{CONCLUSION}

On most occasions, there are multiple thickened peripheral/ cutaneous nerves in suspected cases of leprosy, but neurological deficits pertaining to the thickened nerve are usually not as much widespread. It is important to select the nerve which has deficits in relation to its distribution. Polymerase chain reaction for the identification of $M$. leprae DNA should become a routine practice to confirm all suspected cases of leprosy so that delayed diagnosis and mislabeling and active transmission is reduced. It may be extended to all nerve biopsies in endemic regions. The limitations of the current study are as follows: samples included are from a highly biased set of patients who visit a quaternary care neurological center. Nevertheless, the findings have significant clinical, diagnostic, and therapeutic implications.

Received October 8, 2019. Accepted for publication March 1, 2020.

Published online April 13, 2020.

Acknowledgments: We immensely thank all the patients for permitting us to publish the medical data. The American Society of Tropical Medicine and Hygiene (ASTMH) assisted with publication expenses.

Authors' addresses: Seena Vengalil, Saraswati Nashi, Veeramani Preethish-Kumar, Kiran Polavarapu, Niranjan Prakash Mahajan, Sanita Raju, Chevula Pradeep-Chandra-Reddy, Muddasu Keerthipriya, Anita Mahadevan, Tagadur Chickabasaviah Yasha, Bevinahalli Nandeesh, Krishnamurthy Gnanakumar, and Atchayaram Nalini, 
Department of Neurology, National Institute of Mental Health and Neurosciences, Bangalore, India, E-mails: seenavengali@@gmail.com, nandanashi@gmail.com, prthshkumar@gmail.com, kinnudreamz@ gmail.com, niranjan_npm@yahoo.co.in, sanita.raju2@gmail.com, pradeep.medico92@gmail.com, missypriya@gmail.com, anita@maadh. com, yasha_muthane@yahoo.co.in, nandeeshbn@gmail.com, gnani. abc@gmail.com, and atchayaramnalini@yahoo.co.in. Mallika Lavania, Itu Singh, and Utpal Sengupta, Stanley Browne Research Laboratory, TLM Community Hospital, New Delhi, India, E-mails: mallikalavania@ gmail.com, itusingh@gmail.com, and usengupta2002@yahoo.com. Gareth J Parry, Department of Neurology, St John's Medical College, Bangalore, India, E-mail: minnparry@gmail.com.

\section{REFERENCES}

1. Britton WJ, Lockwood DNJ, 2004. Leprosy. Lancet Lond Engl 363: 1209-1219.

2. Desikan KV, 2012. Elimination of leprosy \& possibility of eradication - the Indian scenario. Indian J Med Res 135: 3-5.

3. WHO/Department of Control of Neglected Tropical Diseases, 2014. Global leprosy update, 2013; reducing disease burden. Wkly Epidemiol Rec 36: 389-400.

4. World Health Organization, 2012. WHO expert committee on leprosy. World Health Organ Tech Rep Ser 968: 1-61.

5. Yawalkar SJ, 2009. Leprosy for Medical Practitioners and Paramedical Workers, 8th revised ed. Basle, Switzerland: Novartis Foundation for Sustainable Development.

6. de Freitas MRG, Nascimento OJM, Quaglino EAM, Oliveira A, Hahn MD, 2003. Small-fiber polyneuropathy in leprosy without skin changes: study of 17 cases. Arq Neuropsiquiatr 61: 542-546.

7. Nascimento OJM, Nascimento OJM, 2013. Leprosy neuropathy: clinical presentations. Arq Neuropsiquiatr 71: 661-666.

8. Van Brakel WH, Nicholls PG, Das L, Barkataki P, Maddali P, Lockwood DNJ, Wilder-Smith E, 2005. The INFIR Cohort Study: assessment of sensory and motor neuropathy in leprosy at baseline. Lepr Rev 76: 277-295.

9. Smith WCS et al., 2009. Predicting neuropathy and reactions in leprosy at diagnosis and before incident events-results from the INFIR cohort study. PLoS Negl Trop Dis 3: e500.

10. Pannikar $V, 2009$. Enhanced global strategy for further reducing the disease burden due to leprosy: 2011-2015. Lepr Rev 80: 353-354.

11. Pearson JM, Ross WF, 1975. Nerve involvement in leprosypathology, differential diagnosis and principles of management. Lepr Rev 46: 199-212.

12. Indian association of leprologists, 1955 . Classification of leprosy adopted at all India leprosy workers conference. Lepr India 27: 93.

13. Garbino J, Jardim M, Marques Jr. W, 2013. Hanseníase neural primária-revisão sistemática. Projeto diretrizes. AMB/CFM. Arq. Neuro-Psiquiatr 71: 397-404.

14. Garbino JA et al., 2013. Primary neural leprosy: systematic review. Arq Neuropsiquiatr 71: 397-404.

15. Garbino JA, 2007. O paciente com suspeita de hanseníase primariamente neural. Hansen Int 32: 203-206.

16. Girdhar BK, 1996. Neuritic leprosy. Indian J Lepr 68: 35-42.

17. Jardim MR et al., 2003. Criteria for diagnosis of pure neural leprosy. J Neurol 250: 806-809.

18. Rao PN, Suneetha S, 2016. Pure neuritic leprosy: current status and relevance. Indian J Dermatol Venereol Leprol 82: 252.

19. Bezerra Da Cunha FM, Werneck MCM, Scola RH, Werneck LC, 2006. Pure neural leprosy: diagnostic value of the polymerase chain reaction. Muscle Nerve 33: 409-414.

20. Jardim MR et al., 2005. Role of PGL-I antibody detection in the diagnosis of pure neural leprosy. Lepr Rev 76: 232-240.

21. Wichitwechkarn J, Karnjan S, Shuntawuttisettee S, Sornprasit C, Kampirapap K, Peerapakorn S, 1995. Detection of Mycobacterium leprae infection by PCR. J Clin Microbiol 33: 45-49.

22. Job CK, Jayakumar J, Williams DL, Gillis TP, 1997. Role of polymerase chain reaction in the diagnosis of early leprosy. Int $J$ Lepr Other Mycobact Dis 65: 461-464.

23. Rodriguez G, Pinto R, Gomez Y, Rengifo ML, Estrada OL, Sarmiento M, Lopez F, Beltran-Alzate JC, Cardona-Castro N,
2013. Pure neuritic leprosy in patients from a high endemic region of Colombia. Lepr Rev 84: 41-50.

24. Bhushan P, Sardana K, Koranne RV, Choudhary M, Manjul P, 2008. Diagnosing multibacillary leprosy: a comparative evaluation of diagnostic accuracy of slit-skin smear, bacterial index of granuloma and WHO operational classification. Indian $J$ Dermatol Venereol Leprol 74: 322.

25. Baptista I, Sartori B, Trino L, 2006. Guia de conduta para realização do exame baciloscópico. Hansen Int 31: 39-41.

26. Kaur G, K Girdhar B, Girdhar A, Malaviya G, Mukherjee A, Sengupta U, V Desikan K, 1991. A clinical study of neuritic leprosy patients. Int J Lepr Other Mycobact Dis 59: 385-391.

27. Mahajan PM, Jogaikar DG, Mehta JM, 1996. A study of pure neuritic leprosy: clinical experience. Indian J Lepr 68: 137-141.

28. Noordeen S, 1972. Epidemiology of (poly) neuritic type of leprosy. Lepr India 44: 90-96.

29. Dayal R, Agarwal M, Natrajan M, Katoch VM, Katoch K, Singh K, Chauhan DS, 2007. PCR and in-situ hybridization for diagnosis of leprosy. Indian J Pediatr 74: 645-648.

30. Dharmendra, Ramanujam K, Ramu G, 1986. Pure polyneuritic leprosy of tuberculoid type. Lepr India 38: 152-158.

31. Nations SP, Katz JS, Lyde CB, Barohn RJ, 1998. Leprous neuropathy: an American perspective. Semin Neurol 18: 113-124.

32. Pannikar VK, Arunthathi S, Chacko CJ, Fritschi EP, 1983. A clinico-pathological study of primary neuritic leprosy. LeprIndia 55: 212-221.

33. Suneetha S, Arunthathi S, Chandi S, Kurian N, Chacko CJ, 1998. Histological studies in primary neuritic leprosy: changes in the apparently normal skin. Lepr Rev 69: 351-357.

34. Hackel C, Houard S, Portaels F, van Elsen A, Herzog A, Bollen A, 1990. Specific identification of Mycobacterium leprae by the polymerase chain reaction. Mol Cell Probes 4: 205-210.

35. Santos AR, De Miranda AB, Sarno EN, Suffys PN, Degrave WM, 1993. Use of PCR-mediated amplification of Mycobacterium leprae DNA in different types of clinical samples for the diagnosis of leprosy. J Med Microbiol 39: 298-304.

36. Woods SA, Cole ST, 1989. A rapid method for the detection of potentially viable Mycobacterium leprae in human biopsies: a novel application of PCR. FEMS Microbiol Lett 53: 305-309.

37. Martinez AN, Talhari C, Moraes MO, Talhari S, 2014. PCR-based techniques for leprosy diagnosis: from the laboratory to the clinic. PLoS Negl Trop Dis 8: e2655.

38. Polavarapu K et al., 2019. Brain and spinal cord lesions in leprosy: a magnetic resonance imaging-based study. Am J Trop Med Hyg 100: 921-931.

39. Tiwari V, Malhotra K, Khan K, Maurya PK, Singh AK, Thacker AK, Husain N, Kulshreshtha D, 2017. Evaluation of polymerase chain reaction in nerve biopsy specimens of patients with Hansen's disease. J Neurol Sci 380: 187-190.

40. Nagappa M, Chickabasaviah YT, Mahadevan A, Parthiban R, Taly $A B, 2015$. Pitfalls in the diagnosis of leprous neuropathy: lessons learnt from a University hospital in an endemic zone. J Neurol Sci 357: 252-256.

41. Chemouilli P, Woods S, Said G, Cole ST, 1996. Detection of Mycobacterium leprae in nerve lesions by the polymerase chain reaction. Int J Lepr Other Mycobact Dis 64: 1-5.

42. Antunes SLG, Chimelli L, Jardim MR, Vital RT, Nery JA da C, Corte-Real S, Hacker MAVB, Sarno EN, 2012. Histopathological examination of nerve samples from pure neural leprosy patients: obtaining maximum information to improve diagnostic efficiency. Mem Inst Oswaldo Cruz 107: 246-253. https://doi.org/10.1590/s0074-02762012000200015.

43. Kurabachew M, Wondimu A, Ryon JJ, 1998. Reverse transcription-PCR detection of Mycobacterium leprae in clinical specimens. J Clin Microbiol 36: 1352-1356.

44. Visser LH, Jain S, Lokesh B, Suneetha S, Subbanna J, 2012. Morphological changes of the epineurium in leprosy: a new finding detected by high-resolution sonography. Muscle Nerve 46: 38-41. https://doi.org/10.1002/mus.23269.

45. Jain S, Visser LH, Yerasu MR, Raju R, Meena AK, Lokesh B, Suneetha S, 2013. Use of high resolution ultrasonography as an additional tool in the diagnosis of primary neuritic leprosy: a case report. Lepr Rev 84: 161-165. 